\title{
Penaklukan Konstantinopel tahun 1543: Upaya Turki Utsmani menyebarkan agama dan membentuk kebudayaan Islam di Eropa
}

\author{
Yolan Sadewa Aditya Kusuma, Lutfiah Ayundasari* \\ Universitas Negeri Malang, Jl. Semarang No. 5 Malang, Jawa Timur, Indonesia \\ *Penulis korespondensi, Surel: lutfiah.ayundasari.fis@um.ac.id
}

Paper received: 03-01-2021; revised: 15-01-2021; accepted: 30-01-2021

\begin{abstract}
Muhammad Al-Fatih, the 22-year-old leader of the Ottoman Empire, has learned a lot from the failure of his predecessors in trying to conquer Constantinople, so that when he came to power in $1451 \mathrm{AD}$ Muhammad Al-Fatih immediately set his sights and was serious about conquering Constantinople, until he was conquered in $1453 \mathrm{AD}$. So that Islam successfully spread to Constantinople, Islam which has entered Constantinople over time will have an impact on local culture which was previously European Roman style, when Constantinople was conquered and Islam entered its culture Identical to the Ottoman Turkish Islamic culture. It is proven by Muhammad Al-Fatih that he immediately changed the magnificent Aya Shofia church to be converted into a mosque and changed the name of the city to Islam Bul which means Islamic city.
\end{abstract}

Keywords: Constantinople; Turkey Utsmani; religion; culture

\begin{abstract}
Abstrak
Muhammad Al-Fatih yang berusia 22 tahun pemimpin Kekhalifanan Turki Utsmani telah banyak belajar dari kegagalan para pendahulunya dalam usaha menaklukkan Konstantinopel, sehingga ketika berkuasa pada tahun 1451 Masehi Muhammad Al-Fatih langsung mengarahkan pandangannya dan bersungguhsungguh untuk menaklukan Konstantinopel, hingga berhasil ditaklukkan pada tahun 1453 Masehi. Sehingga Agama Islam berhasil tersebarke Konstantinopel, Agama Islam yang telah masuk didalam Konstantinopel berjalannya waktu akan berdampak pada kebudayaan setempat yang sebelumnya bergaya Romawi eropa, ketika Konstantinopel ditaklukan dan Islam masuk kebudayaannya Identik dengan kebudayaan Islam Turki Utsmani. Dibuktikan dengan Muhammad Al-Fatih langsung mengubah gereja megah Aya Shofia untuk dialihfungsikan menjadi masjid dan mengganti nama kota menjadi Islam Bul yang bearti kota Islam.
\end{abstract}

Kata kunci: Kostantinopel; Turki Utsmani; agama; kebudayaan

\section{Pendahuluan}

Perluasan Wilayah yang dilakukan umat Islam sudah berlangsung sejak zaman Nabi Muhammad SAW. Salah satu cara yang dilakukan Nabi adalah dengan mengirimkan beberapa Surat dan utusan kepada para raja dan amir (gubernur) untuk menyeru mereka agar mengesakan Allah dan beriman kepada risalah yang diembannya. Cara lain yang ditempuh oleh Nabi Muhammad SAW adalah dengan berperang. Akan tetapi perang tidak disyari'atkan melainkan hanya sebagai langkah membela diri, kehormatan dan harta benda (Hasan, 2001: 410). Kejayaan Kekhalifaan Islam sempat naik turun pada abad ke 14.

Pada abad pertengahan keadaan politik umat Islam secara keseluruhan baru mengalami kemajuan kembali setelah muncul dan berkembangnya tiga kerajaan besar: Usmani di Turki, Mughal di India, dan Safawi di Persia. Dari ketiga kerajaan besar ini, Kerajaan Usmani lah yang terbesar dan paling lama bertahan dibanding dua kerajaan lainnya (Sari, 2011). Kekuasaan 
Islam terakhir yang menamakan dirinya Khilafah yaitu Khilafah Usmaniyah atau sering disebut Kesultanan Turki Usmani. Khilafah Usmaniyah berawal dari sebuah kabilah pengembara yang mendiami wilayah Asia Tengah, yaitu Turkistan. Mereka termasuk suku Kayi. Karena kekejaman bangsa Mongol yang menyerang dunia Islam, pemimpin suku Kayi, Sulaiman Syah, yang mengajak anggota sukunya untuk menghindari serbuan bangsa Mongol dan lari ke arah barat. Kawanan pengembara itu lalu terpecah menjadi dua kelompok: mereka yang ingin kembali ke daerah asalnya dan mereka yang ingin meneruskan perjalanan ke Asia Kecil. Kelompok kedua yang berjumlah 400 keluarga sepakat mengangkat Erthogrul sebagai pemimpin mereka. Kemudian mereka mengabdikan diri kepada Sultan Alauddin II dari Turki Saljuk Rum (Didin, 2009: 228-229). Pada saat masa kesultanan Muhammad II (Al-Fātiȟ) yang berkuasa pada tahun 1451-1481M. Keberhasilan utamanya adalah menguasai Ibu Kota Byzantium, Konstantinopel. Karena pembebasan Konstantinopel adalah cita-cita besar yang ada di Benak kaum muslim sejak mereka menegakkan Negara Khilafah yaitu pada masa Khulafah Ar Rasyidun (Abdul, 2006: 219).

Jatuhnya Konstantinopel menandai akhir riwayat Kekaisaran Byzantium, yang dipandang sebagai salah satu penguasa adikuasa sebelum Islam muncul. Konstantinopel berada disebuah tempat yang secara geografis sangat istimewa, karena berada di atas tujuh bukit di mana orang dapat melihat secara leluasa. Kota ini juga terletak di perbatasan Eropa dan Asia yang merupakan persimpangan jalan antara belahan bumi bagian Barat dan Timur, dan di antara Laut Hitam dan Laut Tengah. Konstantinopel dikenal memiliki cuaca yang berfariasi serta dilindungi oleh dinding tebal dan benteng yang kokoh, yang berfungsi untuk menahan serangan dari orang-orang Berber, Rusia, dan Bulgaria. Kota ini merupakan tempat yang sulit diserang oleh orang-orang Arab, Persia, dan bangsa- bangsa lainnya (Abdul, 2006: 218).

Pada hari Kamis 26 Rabiul Awal 857 H atau 6 April 1453 M, pasukan Islam yang dipimpin langsung oleh Sultan Al-Fātih dapat mengepung sekeliling kota Konstantinopel. Beliau membangun sebuah benteng yang letaknya bersebrangan dengan benteng yang dibangun oleh Khalifah Bayazid I yaitu Benteng Anaduli Hisar dan Rumilia Hisar, yang mampu menguasai dan mengamankan Selat Bosporus dan pintu masuk ke Laut Hitam. Beliau juga berhasil membunuh Kaisar Byzantium dalam peperangan. Kemenangan ini merupakan terbesar bagi Utsmaniyah. Sehingga persebaran Agama Islam dieropa kembali mengalami titik terang ketika Konstantinopel berhasil ditaklukan, Persebaran Agama Islam ini akan sangat merubah wajah Konstantinopel khusunya dalam kebudayaan yang sebelumnya Bergaya Kristen akan Identik dengan Agama Islam.

Setelah ditaklukkannya Konstantinopel banyak perubahan yang terjadi di dalam kota itu, di antaranya Gereja Aya Sophia diubah menjadi Mesjid. Muhammad Al-Fatih juga membangun Mesjid yang diberi nama Mesjid Muhammad sebagai tanda keberhasilannya menaklukkan kota itu. Konstantinopel pun dijadikan Ibukota Kerajaan Utsmani, yang sebelumnya berpusat di Edirne. Nama Konstantinopel pun kemudian diubah menjadi Istambul (kota Islam) (Didin, 2009: 232).

\section{Metode}

Penelitian dilakukan dengan menggunakan metode kualitatif dengan pengumpulan data berupa studi pustaka. Pengumpulan data dilakukan dengan mencari sumber berupa buku dan riset jurnal-jurnal yang tersedia di internet. Serta melakukan kritik-kritik terhadap berbagai 
sumber agar menghindari dari plagiasi. Penelitian ini juga melanjutkan dari berbagai penelitian sebelumnya, sehingga dapat dikembangkan dengan kelebihan-kelebihan yang ada.

\section{Hasil dan Pembahasan}

\subsection{Latar Belakang Penaklukan Konstantinopel}

Konstantinopel dipandang sebagai salah satu kota paling penting di dunia, didirikan pada tahun $330 \mathrm{M}$ oleh Kaisar Byzantium, Constantine I. Kota itu menjadi tempat unik dan menawan di dunia. Ketika kaum Muslimin mulai berjihad melawan Kekaisaran Byzantium, Kota Konstantinopel mempunyai aspek khusus dalam pertsarungan itu. oleh karena itu, Rasulullah SAW menyampaikan berita gembira kepada para sahabatnya mengenai akan ditaklukannya Konstantinopel. Diantaranya ketika berlangsung perang Khandaq, beliau bersabda : Sesungguhnya kota Konstantinopel pasti akan ditaklukan oleh seseorang. Pemimpin yang menaklukannya adalaha sebaik-baiknya pemimpin dan pasukannya adalah sebaik-baiknya pasukan. Oleh sebab itu, Pembebasan Konstantinopel adalah cita-cita besar yang ada di Benak kaum muslim sejak mereka menegakkan Negara Khilafah yaitu pada masa Khulafah Ar Rasyidun. Hal itu tidak lepas dari faktor bahwa Kaum Muslim sebelumnya pernah mencoba beberapa kali untuk membebaskan kota tersebut. Usaha-usaha yang pernah dilakukan Kaum Muslim dalam menaklukan Konstantinopel antara lain Usaha pertama dilakukan pada masa Mu'awiyah bin Abi Sufyan sepanjang masa 49 - 52 H, namun menemui kegagalan, Usaha kedua pada masa Sulaiman bin Abdul Malik dari Bani Umayyah. Dia telah mengepung akan tetapi tidak berhasil karena persenjataan mereka masih kurang lengkap, Pada masa Dinasti Utsman Khalifah Bayazid I dan Khalifah Murad II kembali mengepung Konstantinopel, akan tetapi karena persiapannya kurang matang akhirnya mengalami kegagalan (Sari, 2011).

Setelah itu, beberapa negara kecil di Asia kecil, di antaranya yang paling sering adalah negara Saljuk, berusaha untuk menaklukannya. Negara Saljuk mampu megalahkan Kaisar Romawi dan menawan kaisarnya dan mengharuskan membayar jisyah kepada Sulthan Saljuk. Hal ini pertanda tunduknya sebagian besar Kekaisaran Romawi terhadap Daulah Islam Saljuk. Setelah Saljuk melemah, maka muncullah Saljuk kecil lainnya, yaitu Saljuk Romawi.

Setelah melemahnya Saljuk Romawi, maka muncullah Bangsa Utsmani pada abad $8 \mathrm{H}$ atau 14 M. Berbagai upaya dilakukan oleh Daulah Utsmaniyah khususnya pada masa Sulthan Bayazid pada tahun 796 M (1393 M) dimana Konstantinopel terkepung oleh pasukan Islam dengan sangat rapi. Sultan Bayazid sempat berunding dengan Kaisar Byzantium untuk menyerahkan kota ini dengan damai tanpa adanya peperangan. Akan tetapi Kaisar Byzantium menunda-nunda, dan berusaha meminta bantua negara-negara Eropa untuk menghadpi serangan pasukan Islam terhadap Konstantinopel. Pada waktu yang sama, tentara Mongol Islam yang dipimpin Timur Lenk telah sampai kedalam wilayah-wilayah Daulah Utsmaniyah. Sultan Bayazid terpaksa menarik pasukannya dari pengepungan Konstantinopel untuk menghadapi pasukan Mongol Timur Lenk. Maka berkobarlah perang Ankarayang sangat masyhur antara kedua pasukan itu. peperangan ini dimenangkan oleh Timur Lenk, dan Sultan Bayazid tewas dalam perang ini pada tahun 1402 M yang mengakibatkan Daulah Utsmaniyah tercerai berai sampai terjadi perang saudara.

Setelah keadaan Daulah Utsmaniyah kembali stabil dibawah kepemimpinan Sultan Murad II, Konstantinopel kembali coba ditaklukan. Tetapi Kaisar Byzantium berusaha menimbulkan fitnah di kalangan orang-orang Utsmani, yang mengakibatkan Sultan Murad II 
sibuk dengan urusan dalam negeri. Generasi emas Daulah Utsmaniyah akhirnya muncul pada masa pemerintahan Muhammad Al-Fatih, yang diangkat menjadi penguasa ketika umurnya baru 22 tahu. Muhammad Al-Fatih telah banyak belajar dari kegagalan para pendahulunya dalam usaha menaklukkan Konstantinopel, sehingga ketika berkuasa pada tahun 1451 Masehi Muhammad Al-Fatih langsung mengarahkan pandangannya dan bersungguhsungguh untuk menaklukan Konstantinopel, hingga berhasil ditaklukkan pada tahun 1453 Masehi (AshShalabi, 2003: 107). Muhammad Al Fatih memiliki banyak alasan yang kuat untuk menaklukan Konstantinopel diantaranya Dinasti Utsmani ingin menguasai kegiatan perdagangan internasional di kawasan Konstantinopel, Muhammad Al Fatih ingin meruntuhkan dominasi Byzantium Romawi Timur di kawasan Timur Tengah, Menegaskan kekuatan pengaruh serta menyebarkan Agama Islam di dunia Internasional.

\subsection{Jatuhnya Konstantinopel Ke Turki Utsmani}

Muhammad Al-Fatih merupakan kunci utama keberhasilan penaklukan terhadap Konstantinopel pada tahun 1453 Masehi. Adapun usaha-usaha atau peranan Muhammad AlFatih dalam pembebasan Konstantinopel adalah menambah personil militer dan memperkuat armada laut, membangun benteng Romali Hishar, menghimpun persenjataan, mengadakan perjanjian damai dengan beberapa negara rival, memimpin pengepungan Konstantinopel atau sebagai panglima perang, menyebarkan dakwah Islam ke seluruh Konstantinopel dan sekitarnya (Sarkowi, 2016).

Daulah Bani Utsmaniyah sangat terkenal akan kebesaran dan kekuatan militernya, baik dari segi jumlah personil maupun dari segi kualitas dan semangat tempurnya yang sangat tinggi dan mencapai puncaknya pada masa Sultan Muhammad Al-Fatih. Sultan Al-Fatih sangat memperhatikan personil perangnya hingga berhasil menghimpun dan mengorganisir lebih 250.000 personil tentara yang terdidik dan terlatih secara matang. Untuk menaklukkan Konstantinopel Muhammad Al-Fatih benar-benar telah menyiapkan pasukan atau tentara dalam jumlah yang sangat besar, agar cita-citanya untuk menaklukkan Konstantinopel benarbenar terwujud. Berg dkk (1952: 309) menuliskan "tentara yang mengepung kota dari darat terdiri dari dua sampai tiga ratus ribu prajurit". Artinya pasukan Utsmani yang disiapkan oleh Al-Fatih untuk menggempur Konstantinopel merupakan jumlah yang sangat besar. Muhammad Al-Fatih juga memperkuat armada angkatan laut, karena laut adalah jalan satusatunya untuk dapat menaklukkan Konstantinopel. Beragam kapal telah siapkan, bahkan jumlahnya mencapai sekitar 400 kapal (Ash-Shalabi, 2003: 110-111). AlFatih melakukan gebrakan besar-besaran dalam membenahi angkatan lautnya, baik dari segi personil maupun jumlah kapal perangnya.

Dalam usaha penaklukan Konstantinopel Muhammad Al-Fatih langsung memimpin dan mengorganisir pasukannya sebagai panglima militer tertinggi meskipun demikian ia mengangkat panglima perang atau jenderal-jenderal dalam memimpin peperangan disetiap pasukan. Dalam pengepungan ini, Al-Fatih mengorganisir dan memantau langsung pasukan Utsmani tersebut, bahkan ia sangat memperhatikan perbekalan tentaranya, baik persenjataan maupun logistik (Buchori, 2009: 234). Konstantinopel merupakan kota yang sangat kokoh, dikelilingi oleh benteng. Dilihat dari kekokohannya, kecil sekali kemungkinan untuk bisa menembus benteng tersebut, namun Al-Fatih benar-benar seorang panglima yang ulung, sebelum melakukan penyerangan ia mempersiapkan peta dan menyusun strategi yang matang untuk keberhasilan pengepungan ini. ArRasyidi (dalam Ash-Shalabi, 2003:113) menyatakan 
bahwa dia bahkan melakukan pengintaian sendiri kekokohan kota Konstantinopel dan pagarpagarnya. Amin (2009:198) menyebutkan "Sultan mempersiapkan penaklukan terhadap kota Konstantinopel dengan penuh keseriusan. Di pelajari penyebab kegagalan dalam penaklukanpenaklukan sebelumnya. Sultan tidak mau lagi kalah sebagaimana para pendahulunya. Ia lebih dahulu membereskan wilayah-wilayah yang membangkang di Asia Kecil".

Sebelum menggempur Konstantinopel Muhammad Al-Fatih mengirim utusan kepada Kaisar Byzantium agar tunduk di bawah kekuasaan Islam secara damai . Setelah melihat kebulatan tekad Muhammad Al-Fatih untuk menaklukan Konstantinopel Kaisar Konstantine lebih memilih untuk mempertahankan kota itu dari pada menyerahkan kota tersebut kepada pasukan Islam, sehingga pasukan Utsmaniyah terus menggempur Konstantinopel (Mursi, 2008: 219). Pengepungan terhadap Konstantinopel berlangsung cukup lama, hal ini dikarenakan Konstantinopel merupakan kota benteng yang sangat kokoh dan aman dari jangkauan musuh, serta bantuan dari Eropa yang selalu mengalir ke Konstantinopel lewat Tanduk Emas menyebabkan bertambah lamanya pengepungan kota tersebut. Bahkan ketika kapal-kapal Al-Fatih akan memasuki teluk, orang-orang Romawi langsung menutupnya dengan sebuah rantai yang sangat besar yang tidak dapat dilewati (Mursi, 2008: 218).

Muhammad Al-Fatih membagi pasukannya menjadi tiga lapis dari 250.000. Siauw (2012) menjelaskan setelah mempersiapkan meriam raksasa yang melontarkan peluru seberat $700 \mathrm{~kg}$, Al-Fatih lalu mempersiapkan 250.000 total pasukannya yang terbagi menjadi 3, yaitu pasukan laut dengan 400 kapal perang penyerang melalui laut Marmara, kapal-kapal kecil untuk menembus selat Tanduk, dan sisanya melalui jalan darat menyerang dari sebelah barat Konstantinopel, awal penyerangan ini dilakukan pada tanggal 6 April 1453, yang terkenal dengan The Siege of Constantinople.

Setelah berminggu-minggu berperang namun benteng kota Konstantinopel belum juga dapat ditembus, walaupun menggunakan meriam-meriam yang sangat canggih, kemudian AlFatih mengganti komandan armada pasukan laut, Balta Oghlmi dengan Hamzah Pasya, karena dianggap tidak mampu mencegah kapal-kapal Eropa yang mendarat di teluk Tanduk Emas (AshShalabi, 2003: 116-117). Khawatir kapal-kapalnya mendapat serangan dari selatan, maka kemudian Muhammad Al-Fatih memerintahkan pasukannya untuk menarik kapal-kapalnya dari selat Bosporus ke daratan melalui celah salah satu gerbang sebelah Barat kemudian dilabuhkan di Tanduk Emas. Karena salah satu pertahanan yang agak lemah adalah melalui selat Golden Horn yang sudah dirantai hanya dalam waktu semalam 70 lebih kapal bisa memasuki wilayah selat Golden Horn. Pekerjaan ini dilakukan di tengahtengah kelengahan tentara Byzantium dan merupakan cara yang tidak lazim.

Pekerjaan ini diawasi langsung oleh Al-Fatih dari jarak yang aman dan tidak terjangkau oleh pasukan Byzantium. Pekerjaan ini selesai dilakukan dengan waktu hanya satu malam. Pagi hari tanggal 23 Mei 1453, penduduk kota terbangun oleh teriakan takbir dan dentuman meriam pasukan Utsmaniyah dari Tanduk Emas. Dan kini tidak ada lagi penghalang antara pasukan Byzantium yang mempertahan kota dengan dengan pasukan Ustmaniyah. Setelah berhasil memasuki kota benteng tersebut, Muhammad Al-Fatih membagi pasukan menjadi tiga lapis pasukan, yaitu Irregular di lapisan pertama, Anatolian Army di lapisan kedua dan pasukan ketiga yaitu pasukan khusus,Yenisseri. 29 Mei 1453, setelah sehari istirahat perang, Al-Fatih kembali melakukan serangan umum, dengan tiga lapis pasukan, iregular di lapis pertama, Anatolian Army di lapis kedua dan terakhir pasukan Yenisseri. 
Pada tanggal 29 Mei 1453, hari selasa jam satu pagi, serangan umum mulai di lancarkan secara intensif. Serangan di lakukan segala penjuru dengan tiga pasukan yang bergantian. Pada saat yang bersamaan panglima Byzantium Giovanni Guistiniani melarikan diri akibat luka yang sangat parah, sementara Kaisar Konstantine IX Paleologus mati terbunuh dalam pertempuran tersebut oleh Sultan Muhammad Al-Fatih. Pada hari itu juga kota Konstantinpel jatuh ke tangan pasukan umat Islam di bawah Sultan Muhammad Al-Fatih. Mengenai kejatuhan Konstantinopel pada saat serangan umum ini sesuai dengan pendapat Berg dkk (1952: 312), menyebutkan "Ketika diadakan serangan umum, jaitu pada tanggal 29 Mei 1453, dapatlah lima puluh orang pradjurit Jenisseri merebut satu pintu gerbang kota, yang kurang kuat pertahanannya". Sehingga pada tanggal 29 Mei itu juga pasukan Muhammad Al-Fatih berhasil menguasai kota Konstantinopel.

Keberhasilan pasukan Islam di bawah Sultan Muhammad Al-Fatih menaklukan Konstantinopel merupakan suatu hal yang luar biasa bagi pasukan Islam, karena usaha untuk menaklukan kota ini sudah di mulai sejak berabad-abad. Dengan mengalahkan Byzantium dan menaklukkan Konstantinopel Muhammad Al-Fatih telah mengantarkan kesultanan Utsmani dan Peradaban Islam mencapai masa keemasan dan kejayaan.

\subsection{Peran Turki Utsmani Dalam Menyebarkan Agama dan Membentuk Kebudayaan Islam}

Penaklukan Konstantinopel yang dilakukan oleh Muhammad Al-Fatih dan pasukannya, tidak hanya untuk menjadikan takluk di bawah kekuasaan Utsmaniyah saja, melainkan sebagai titik tolak dakwah Islam ke seluruh Eropa, khususnya semenanjung Balkan. Mursi (2008: 218) menyebutkan bahwa "Dia (Muhammad Al-Fatih) sangat bersemangat dalam menyebarkan Islam ke segala penjuru dunia". Dengan demikian dapat dipahami bahwa tujuan utama penaklukan Muhammad Al-Fatih adalah mendakwahkan Islam kepada wilayahwilayah yang telah berhasil dibebaskannya.

Misi dakwah yang dilakukan Muhammad Al-Fatih tergambar saat jatuhnya Konstantinopel, ia langsung mengubah gereja megah Aya Shofia untuk dialihfungsikan menjadi masjid dan mengganti nama kota menjadi Islam Bul yang bearti kota Islam (Mursi, 2008: 219). Tujuan utama pembebasan Konstantinopel adalah untuk menyeru manusia kepada Islam, tentu Muhammad Al-Fatih selalu berpegang teguh terhadap etika atau adab yang ditentukan oleh syariat Islam dalam memperlakukan wilayah yang telah dibebaskan.

Keberhasilan dalam penaklukan Konstantinopel merupakan pembuka bagi perkembangan Islam di Eropa, Ozoyuna (dalam Ash Shalabi, 2003:146) menjelaskannya bahwa "Sebelum ditaklukkan, Konstantinopel menjadi hambatan besar bagi tersebarnya Islam di benua Eropa. Dengan demikian, penaklukannya bearti jalan pembuka bagi Islam untuk masuk ke benua Eropa dengan kekuatan dan kedamaian lebih dari masa-masa sebelumnya". Pasca pembebasan Konstantinopel agama Islam lebih tersebar luas di benua Eropa dengan kekuatan (jihad) dan kedamaian (dakwah) khususnya wilayah semenanjung Balkan, Eropa Timur dan Eropa Tengah (Usairy, 2007: 553).

Karena pembebasan Konstantinopel sebagai titik tolak untuk menyebarkan agama Islam ke seluruh Eropa, sudah tentu pembebasan Konstantinopel yang dilakukan oleh Muhammad Al-Fatih tersebut bukanlah akhir dari pembebasan yang dilakukannya, melainkan sebagai batu loncatan untuk membebaskan wilayah-wilayah lain di benua Eropa bagian Timur tersebut. 
Muhammad Al-Fatih dalam penaklukan Konstantinopel tahun 1453 Masehi telah mengantarkan kesultanan Utsmani mencapai puncak kejayaannya dan tersebarnya Islam ke berbagai bumi Eropa, khusunya didalam Kostantinopel sendiri.

Agama Islam yang telah masuk didalam Konstantinopel berjalannya waktu akan berdampak pada kebudayaan setempat yang sebelumnya bergaya Romawi eropa, ketika Konstantinopel ditaklukan dan Islam masuk kebudayaannya Identik dengan kebudayaan Islam Turki Utsmani. Peradabannya yang Masa Lalu merupakan cikal bakal Peradaban di Eropa. Pada masa kejayaan Islam, Di bawah kepemimpinan Turki Utsmani, Konstantinopel yang kemudian berubah nama menjadi Istanbul dibangun hingga menjadi salah satu pusat kebudayaan Islam dunia.

Diantaranya Kebudayaan Islam yg masih sangat menonjol dan menjadi bukti bagi dunia yaitu masjid-masjid megah yang dibangun Turki Usmani adalah Masjid Sultan Muhammad alFatih, Masjid Biru atau Masjid Sultan Ahmad, dan Masjid Raya Sulaiman. Dan Istana Tapkopi Palace merupakan kediaman resmi Sultan Ottoman Turki selama lebih 600 tahun. Tidak dapat dipungkuri Kebudayaan Islam begitu membekas hingga saat ini, walaupun sebelum Konstantinopel ditaklukan Kebudayaannya masi identik bergaya Romawi Eropa. Ibukota Turki merupakan Ankara, namun keindahan Kota Istanbul dengan jembatan bophorus semakin menghiasi keindahan Turki dan banyak non muslim ikut mengungjungi dan juga ingin Tau mengenai Kebudayaan Islam disana.

\section{Simpulan}

Pada masa KeKhalifahan Turki Utsmani yang dipimpin Muhammad Al-Fatih, yang diangkat menjadi penguasa ketika umurnya baru 22 tahun. Muhammad Al-Fatih telah banyak belajar dari kegagalan para pendahulunya dalam usaha menaklukkan Konstantinopel, sehingga ketika berkuasa pada tahun 1451 Masehi Muhammad Al-Fatih langsung mengarahkan pandangannya dan bersungguhsungguh untuk menaklukan Konstantinopel, hingga berhasil ditaklukkan pada tahun 1453 Masehi. Sehingga Agama Islam berhasil tersebarke Konstantinopel, Agama Islam yang telah masuk didalam Konstantinopel berjalannya waktu akan berdampak pada kebudayaan setempat yang sebelumnya bergaya Romawi eropa, ketika Konstantinopel ditaklukan dan Islam masuk kebudayaannya Identik dengan kebudayaan Islam Turki Utsmani. Dibuktikan dengan Muhammad Al-Fatih langsung mengubah gereja megah Aya Shofia untuk dialihfungsikan menjadi masjid dan mengganti nama kota menjadi Islam Bul yang berarti kota Islam.

\section{Daftar Rujukan}

As-Shinnawy, A. A. (2006). Pembebasan Islam. Terj. Abu Faiz. Bogor: Pustaka Thariqul Izzah.

Ahmad, A. U. (2007). Sejarah Islam Sejak Zaman Nabi Adam Hingga Abad XX. Jakarta: Akbar Media Eka Sarana Amin, M. (2009). Sejarah Peradaban Islam. Jakarta: Amzah.

As-Shalabi, A. M. (2003). Bangkit dan Runtuhnya Khilafah Utsmaniyah, terj. Samson Rahman, Pustaka Kautsar: Jakarta.

Berg, H.J.Van Den dkk. (1952). Sejarah Dunia, Jilid II; Sejarah Negeri-negeri Sekitar Laut Tengah dan Sejarah Eropah Sampai Tahun 1500 Tarik Masehi. Jakarta: Hilversum

Buchori, D. S. (2009). Sejarah Politik Islam. Jakarta: Pustaka Intermasa

Ibrahim, H. (2001). Sejarah dan Kebudayaan Islam. Jakarta: Kalam Mulia.

Mursi, S. M. S. I. (2007). Tokoh-tokoh Besar Islam Sepanjang Sejarah. Pustaka Al-Kautsar.

Siauw, F. Y. (2012). Muhammad Al-Fatih 1453. Jakarta: Khilafah Press 
Jurnal Integrasi dan Harmoni Inovatif Ilmu-Ilmu Sosial (JIHI3S), 1(1), 2021, 61-68

Sarkowi. (2016). Peran Muhammad Al-Fatih Dalam Penaklukan Konstantinopel Tahun 1453 Masehi. Jurnal STKIP-PGRI Lubuklinggau, 5(10), 147-157.

Sari, S. E. (2011). Keberhasilan Sultan Al-Fatih Dalam Menaklukkan Konstantinopel dan Pengaruhnya Dalam Renaissance di Eropa. Skripsi tidak diterbitkan. Cirebon: IAIN SYEKH NURJATI. 